\title{
Activation of kinin B1 receptor evokes hyperthermia through a vagal sensory mechanism in the rat
}

\author{
Sébastien Talbot ${ }^{\dagger}$, Helaine De Brito Gariépy ${ }^{\dagger}$, Julien Saint-Denis and Réjean Couture*
}

\begin{abstract}
Background: Kinins are mediators of pain and inflammation. Their role in thermoregulation is, however, unknown despite the fact the B1 receptor (B1R) was found implicated in lipopolysaccharide (LPS)-induced fever. The aim of this study was to investigate the mechanism by which peripheral B1R affects body core temperature in a rat model known to show up-regulated levels of B1R.

Methods: Male Sprague-Dawley rats received streptozotocin (STZ, $65 \mathrm{mg} / \mathrm{kg}$; i.p.) to enhance B1R expression. Control rats received the vehicle only. One week later, rectal temperature was measured in awake rats after i.p. injection of increasing doses $\left(0.01\right.$ to $5 \mathrm{mg} / \mathrm{kg}$ ) of des-Arg ${ }^{9}$-Bradykinin (BK) and Sar-[D-Phe ${ }^{8}$ ]des-Arg ${ }^{9}$-BK (B1R agonists) or BK (B2R agonist). The mechanism of B1R-induced hyperthermia was addressed using specific inhibitors and in rats subjected to subdiaphragmatic vagal nerve ligation. B1R mRNA level was measured by quantitative Real Time-polymerase chain reaction (qRT-PCR) and B1R was localized by confocal microscopy.
\end{abstract}

Results: B1R agonists (0.1 to $5 \mathrm{mg} / \mathrm{kg}$ ) showed transient (5- to 30-minute) and dose-dependent increases of rectal temperature $\left(+1.5^{\circ} \mathrm{C}\right)$ in STZ-treated rats, but not in control rats. BK caused no effect in STZ and control rats. In STZ-treated rats, B1R agonist-induced hyperthermia was blocked by antagonists/inhibitors of B1R (SSR240612), cyclooxygenase-2 (COX-2) (niflumic acid) and nitric oxide synthase (NOS) (L-NAME), and after vagal nerve ligation. In contrast, COX-1 inhibition (indomethacin) had no effect on B1R agonist-induced hyperthermia. In STZ-treated rats, B1R mRNA was significantly increased in the hypothalamus and the vagus nerve where it was co-localized with calcitonin-gene-related peptide in sensory C-fibers.

Conclusion: B1R, which is induced in inflammatory diseases, could contribute to hyperthermia through a vagal sensory mechanism involving prostaglandins (via COX-2) and nitric oxide.

Keywords: Kinin B1 receptor, Diabetes, Hyperthermia, Inflammation, Bradykinin, NO, Sensory C-fibers, Thermoregulation

\section{Background}

Heat- or hyperthermia-generating processes are generally ascribed to peripherally formed cytokines which convey information to the hypothalamic preoptic area via the organum vasculosum laminae terminalis [1]. This pathway is associated with high circulating levels of cytokines from the immune system [2]. Hyperthermia can also be induced even with low circulating levels of

\footnotetext{
* Correspondence: rejean.couture@umontreal.ca

${ }^{\dagger}$ Equal contributors

Department of Physiology, Faculty of Medicine, Université de Montréal, C.P. 6128, Succursale Downtown, Montréal QC H3C 3J7, Canada

cytokines through a neuronal mechanism involving direct activation of the vagus nerve [3]. Indeed, vagal sensory afferents represent an important communication pathway between the immune system, the inflammatory site and the brain [4]. Subdiaphragmatic vagotomy was shown to abolish fever [5] and central induction of interleukin-1 $\beta$ (IL-1 $\beta$ ) mRNA [6] after intraperitoneal (i.p.) injection of IL-1 $\beta$ or lipopolysaccharide (LPS).

Kinins are vasoactive peptides involved in pain and inflammation [7-13]. They act through the activation of two G-protein-coupled receptors denoted as B1 (B1R) and B2 (B2R) $[14,15]$. The B2R is widely and constitutively 
expressed in central and peripheral tissues and is activated by bradykinin (BK) and Lys-BK. Their metabolites, des-Arg ${ }^{9}$-BK and Lys-des-Arg' ${ }^{9}$-BK, are the preferential agonists of B1R $[15,16]$. The latter is virtually absent in healthy condition but up-regulated after exposure to pro-inflammatory cytokines, LPS and oxidative stress [9,16-19]. LPS, an endotoxin derived from the cell wall of Gram-negative bacteria, induces fever through cytokine release and Toll-like receptor 4 activation in several species, notably in rats, mice and rabbits $[1,20,21]$. When injected intracerebroventricularly (i.c.v.), B2R antagonist curtailed the early phase ( 0 to $2 \mathrm{~h}$ ) of the febrile response induced by LPS while B1R antagonist inhibited the late phase (4 to 6 h) [22]. These authors also demonstrated that a 24-h pre-treatment with LPS reduced the febrile response induced by BK but enhanced that induced by the B1R agonist des-Arg ${ }^{9}-\mathrm{BK}$ injected i.c.v. In rabbits, BK (i.c.v.) also increased rectal temperature dosedependently, which was partly mediated by prostaglandins (PGs) [23]. Similarly, the stimulation of rat brain B2R caused hyperthermia [24], an effect absent in animals with a bilateral lesion of the hypothalamic paraventricular nucleus [25]. The role of peripheral kinin receptors in fever, however, remains unknown.

Kinin B1R is involved in the main cardinal signs of inflammation, such as pain $[8,11]$, edema and increased vascular permeability $[13,17,26]$ and vasodilatation $[27,28]$ through the release of pro-inflammatory cytokines (IL-1 $\beta$, IL-6) and other mediators (NO, substance P and PGs) $[8,11,12]$. Surprisingly, the role of kinin B1R in the regulation of body core temperature has never been investigated in the periphery. As B1R is virtually absent in control rats, we used streptozotocin (STZ)-treated rats as a model to induce B1R expression [10,29-31]. This study was then undertaken to determine whether intraperitoneal activation of $\mathrm{B} 1 \mathrm{R}$ with selective agonists enhances rectal temperature through a vagal afferent pathway. Pharmacological treatments with inhibitors were administered to determine the contribution of inflammatory mediators (NO, PGs). The expression of $\mathrm{B} 1 \mathrm{R}$ in the hypothalamus and vagus nerve was also determined by quantitative real-time PCR (qRT-PCR) and confocal microscopy.

\section{Methods}

\section{Experimental animal and care}

All research procedures and the care of the animals were in compliance with the guiding principles for animal experimentation as enunciated by the Canadian Council on Animal Care and were approved by the Animal Care Committee of our University. Male Sprague-Dawley rats (200 to 225 g; Charles River, St-Constant, QC, Canada) were housed two per cage under controlled conditions of temperature $\left(23^{\circ} \mathrm{C}\right)$ and humidity $(50 \%)$, on a $12 \mathrm{~h}$ light-dark cycle and allowed free access to a normal chow diet (Charles River Rodent) and tap water.

\section{STZ treatment}

STZ is a chemotherapeutic agent of the glucosaminenitrosourea class, commonly used to treat human Langerhans islet cancer. Since STZ is structurally similar to glucose, it is taken up by glucose transporter 2 (GLUT2) in pancreatic $\beta$-cells leading to their destruction and, thereby, to insulin deficit and hyperglycemia. This condition mimics human type 1 diabetes.

Rats were injected under low light with freshly prepared STZ (65 mg/kg, i.p.; Zanosar, McKesson, Montreal, QC, Canada) [10]. Age-matched controls were injected with the vehicle (sterile saline $0.9 \%, \mathrm{pH} 7.0$ ). Blood glucose was measured with a commercial blood glucose-monitoring kit (Accusoft; Roche Diagnostics, Laval, QC, Canada) from a drop of blood obtained from the tail vein, in non-fasting animals. The impact of oneweek diabetes was assessed on body weight $(\mathrm{g})$, water intake ( $\mathrm{ml} /$ day/rat) and food consumption (g/day/rat).

A total volume of $250 \mathrm{ml}$ of water and 250 grams of chow diet were made available for daily consumption by two rats per cage; $24 \mathrm{~h}$ later the residual amount of water and food was calculated and subtracted from the original amount and divided by two. Thereafter, water bottles were filled up again to $250 \mathrm{ml}$ and food was weighed at 250 grams.

\section{Measurement of body temperature}

Rat body temperature was measured before ( 0 minute) and after drug injections (5, 10, 15, 30 and 60 minutes) with a lubricated flexible digital thermometer delicately inserted into the rat rectum $(2.5 \mathrm{~cm})$ for $10 \mathrm{sec}$. Experiments were conducted daily at 10:00 A.M. by two experienced investigators. Rats were trained to the procedure in a quiet room during the week preceding experiments. STZ-treated and control rats were pre-treated or not with different drugs described in the following section.

\section{Experimental protocols in whole animals}

Des-Arg 9 -BK (DABK) [14] and the peptidase resistant Sar-[D-Phe ${ }^{8}$ ]des-Arg ${ }^{9}$-BK (SDABK) [32] were used as selective B1R agonists ( 0.01 to $5 \mathrm{mg} / \mathrm{kg}$ ) to evaluate the effect of intraperitoneal B1R stimulation on body temperature in control and STZ-treated rats. BK $(1 \mathrm{mg} / \mathrm{kg})$ was used as a B2R agonist [14]. The contribution of NO and PGs in B1R-induced hyperthermia was evaluated after $2 \mathrm{~h}$ pre-treatment with (a) L-NG-Nitroarginine Methyl Ester (L-NAME) (30 $\mathrm{mg} / \mathrm{kg}$, i.p.), a nitric oxide synthase (NOS) inhibitor [33], (b) indomethacin $(10 \mathrm{mg} / \mathrm{kg}$, i.p.), a non-steroidal anti-inflammatory inhibitor [34], or (c) niflumic acid (15 mg/kg, i.p.), a selective cyclooxygenase-2 (COX-2) inhibitor [34]. SSR240612 
[(2R)-2-[((3R)-3-(1,3-benzodioxol-5-yl)-3-[[(6-methoxy-2naphthyl)sulfonyl]amino]propanoyl)amino]-3-(4-[[2R,6S)2,6-dimethylpiperidinyl]methyl]phenyl)-N-isopropyl-Nmethylpropanamide-hydrochloride], a highly potent and selective B1R antagonist [35] was administered by gavage $(10 \mathrm{mg} / \mathrm{kg}) 3 \mathrm{~h}$ prior to SDABK to ascertain the B1R mediated response on hyperthermia. SSR240612 was obtained from Sanofi-Aventis R\&D (Montpellier, France), dissolved in dimethylsulfoxide (DMSO, $0.5 \% \mathrm{v} / \mathrm{v}$ ), ethanol $(5 \% \mathrm{v} / \mathrm{v})$ and Tween- $80(5 \% \mathrm{v} / \mathrm{v})$ and then completed with distilled water [7]. DABK was purchased from Bachem Bioscience, Inc. (King of Prussia, PA, USA) and diluted in sterile saline. SDABK was synthesized at the Biotechnology Research Institute, National Research Council of Canada (Montreal, QC, Canada) and diluted in sterile saline. BK and L-NAME were diluted in sterile saline, while niflumic acid and indomethacin were diluted in 5\% DMSO and 95\% ethanol, respectively. Unless stated otherwise, other reagents were purchased from SigmaAldrich Canada, Ltd (Oakville, ON, Canada).

\section{Subdiaphragmatic vagal ligation}

To investigate the role of the vagus nerve in B1Rinduced hyperthermia, rats underwent subdiaphragmatic vagal nerve ligation [36]. Under isoflurane anesthesia and after a midline laparotomy, the stomach and posterior subdiaphragmatic vagal trunks were exposed, and the proximal parts were ligated with 4-0 silk. Shamoperated rats had the same surgery; the vagus nerve was exposed but not ligated. On the day of surgery and for the two subsequent days, rats received the antibiotics trimethoprime and sulphadiazine (Tribrissen $24 \%, 30 \mathrm{mg} /$ $\mathrm{kg}$, subcutaneously (s.c.), Schering Canada, Inc., Pointe Claire, QC, Canada) and the analgesic ketoprofen (Anafen, $5 \mathrm{mg} / \mathrm{kg}$, s.c., Merial Canada, Inc., Baie d'Urfé, QC, Canada). Rats were housed in individual plastic chambers $(40$ X 23 X $20 \mathrm{~cm})$ in the same standard conditions; they had free access to water and food and were allowed to recover for one week before STZ administration.

\section{Confocal microscopy}

\section{Tissue preparation for microscopy}

One-week STZ and vehicle-treated rats were anesthetised with $\mathrm{CO}_{2}$ inhalation and decapitated. A portion of the subdiaphragmatic vagus nerve $(2.5 \mathrm{~cm})$ was removed, frozen in 2-methylbutane (cooled at $-40^{\circ} \mathrm{C}$ with liquid nitrogen) and stored at $-80^{\circ} \mathrm{C}$. The vagus nerve was mounted in a gelatin block and serially cut into $20-\mu \mathrm{m}$ thick coronal sections with a cryostat. Sections were thaw-mounted on $0.2 \%$ gelatin- $0.033 \%$ chromium potassium sulfate-coated slides and kept at $-80^{\circ} \mathrm{C}$ for one month to allow sections to adhere to the coverslip glasses.

\section{Slide preparation}

On the day of the experiments, sections were thawed at room temperature for 10 minutes to enhance section adhesion. Slides were washed for 10 minutes in phosphate buffered saline (PBS) (pH 7.4), fixed in PBS 4\% paraformaldehyde and washed three times ( 5 minutes). Then, sections were permeabilized for 45 minutes in PBS 0.5\% Triton X-100.

\section{Immunolabeling protocol}

Slides were incubated with a blocking buffer (PBS supplemented with $0.5 \%$ Triton X-100, 3\% bovine serum albumin (BSA) and 3\% donkey serum) to prevent nonspecific labeling. Primary antibodies were diluted in the blocking buffer. To generate the B1R antibody, an epitope of 15 amino acids (VFAGRLLKTRVLGTL) localized in the C-terminal part of the B1R protein was injected into rabbits (Biotechnology Research Institute, Montreal, QC, Canada). Care was taken to avoid an epitope sequence region similar to $\mathrm{B} 2 \mathrm{R}$ or other rodent proteins. The specificity of this antibody used at 1:1,500 dilution [37] was confirmed by the absence of the $37 \mathrm{kDa}$ band (putative molecular weight of rat B1R) with the pre-immune serum or with immune serum in B1R knock-out mice renal tissues (data not shown). Mouse anti-calcitonin-gene-related peptide (CGRP) (Chemicon, Hornby, ON, Canada) was diluted at 1:2,000 and used as a specific marker of peptidergic C-fibers [31]. Secondary antibodies were alexa fluor 488 anti-rabbit (Chemicon) diluted 1:1,000 and rhodamine anti-mouse (Chemicon) diluted 1:1,000 [31]. Slides were washed three times (5 minutes), mounted with coverslips, fixed with Vectashield (Invitrogen Life technologies, Burlington, ON, Canada) (12 h at room temperature) and stored at $-4^{\circ} \mathrm{C}$ until examination under a confocal microscope (Leica Confocal Microscope, Richmond Hill, ON, Canada).

\section{SYBR green-based quantitative RT-PCR}

Control and one-week STZ-treated rats were anesthetized with $\mathrm{CO}_{2}$ inhalation and decapitated. Subdiaphragmatic vagus nerve $(2.5 \mathrm{~cm})$ and hypothalamus $(10 \mathrm{mg}$ of tissue) were identified, carefully dissected out and put in RNAlater stabilization reagent (QIAGEN, Valencia, CA, USA). Protocols for mRNA extraction, cDNA generation, SYBR green-based quantitative RT-PCR and quantification were described elsewhere [10]. The PCR conditions were as follows: $95^{\circ} \mathrm{C}$ for 15 minutes, followed by amplification cycles at $94^{\circ} \mathrm{C}$ for $15 \mathrm{~s}, 60^{\circ} \mathrm{C}$ for $30 \mathrm{~s}$ and $72^{\circ} \mathrm{C}$ for $30 \mathrm{~s}$. The Vector NTI-designed RT-PCR primer pairs used in this study are presented in Table 1.

\section{Statistical analysis}

Data were expressed as the means \pm S.E.M. of values obtained from $n$ rats. Statistical significance was determined 
Table 1 qPCR primer pairs used in this study

\begin{tabular}{|c|c|c|c|c|c|c|c|}
\hline & \multicolumn{3}{|c|}{ Sequences } & \multicolumn{3}{|c|}{ Position } & \multirow{2}{*}{$\begin{array}{c}\text { GenBank } \\
\text { X01117 }\end{array}$} \\
\hline 185 forward & $5^{\prime}$ & TCA ACT TTC GAT GGT AGT CGC CGT & $3^{\prime}$ & 363 & - & 386 & \\
\hline 185 reverse & $5^{\prime}$ & TCC TTG GAT GTG GTA GCC GTT TCT & $3^{\prime}$ & 470 & - & 447 & \\
\hline B1 receptor forward & $5^{\prime}$ & GCA GCG CTT AAC CAT AGC GGA AAT & $3^{\prime}$ & 367 & - & 391 & NM_030851 \\
\hline B1 receptor reverse & $5^{\prime}$ & CCA GTT GAA ACG GTT CCC GAT GTT & $3^{\prime}$ & 478 & - & 454 & \\
\hline
\end{tabular}

with unpaired Student's $t$-test or with one-way analysis of variance (ANOVA) followed by post-hoc Bonferroni test for multiple comparisons. Only probability $(\mathrm{p})$ values less than 0.05 were considered to be statistically significant.

\section{Results}

\section{Diabetic status and B1R mRNA expression}

Blood glucose, body weight, water intake and food consumption were measured to confirm the diabetic status of STZ-treated rats. As expected, a significant increase in blood glucose and water intake occurred in one-week STZ rats when compared to age-matched control animals. However, body weight gain and food consumption remained unaffected (Figure 1). B1R mRNA levels were significantly enhanced (four- to five-fold) in the subdiaphragmatic vagus nerve and hypothalamus of STZtreated rats when compared to control rats (Figure 2). The up-regulation of B1R mRNA was not significantly affected by vagal nerve ligation in STZ-treated rats (Figure 2).

\section{B1R localization in the vagus nerve}

B1R immunostaining was almost undetectable in the control subdiaphragmatic vagus nerve (Figure $3 \mathrm{~A}, \mathrm{D}$ ), whereas it was markedly enhanced in STZ-treated rat sections (Figure 3A', D'). Moreover, B1R was found partly co-localized with CGRP-expressing sensory Cfibers of the vagus nerve in STZ rat (Figure $\left.3 \mathrm{C}^{\prime}, \mathrm{F}^{\prime}\right)$. The
A
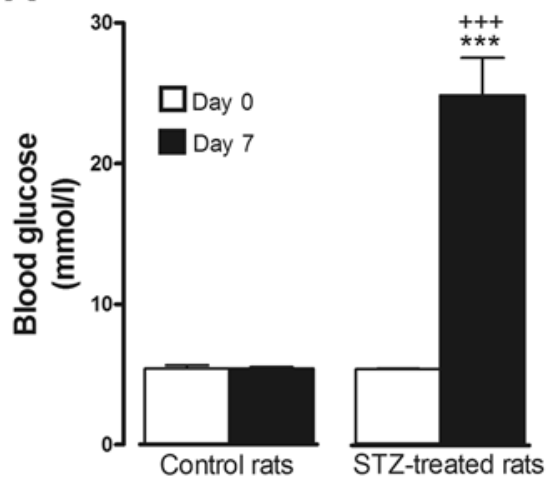

C

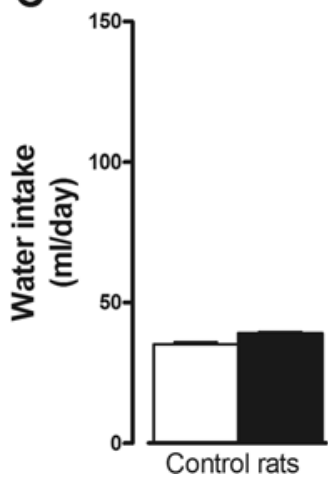

B

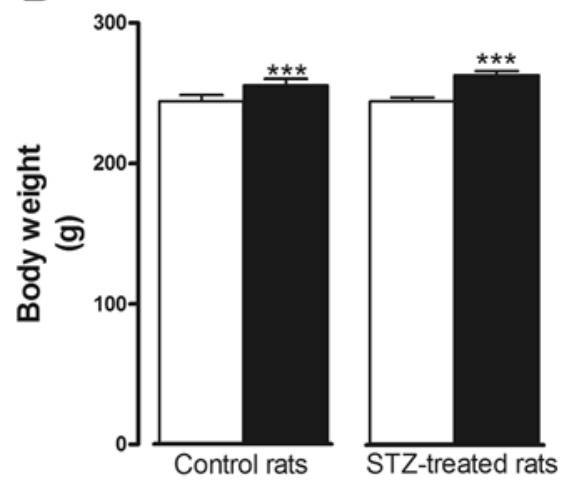

D

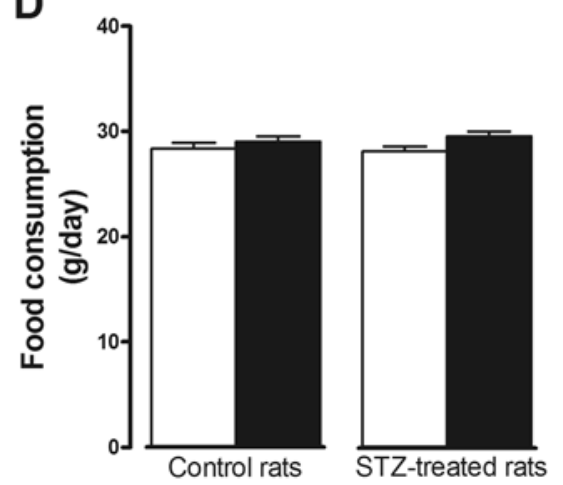

Figure 1 Physiological parameters in control and STZ-treated rats. Values of (A) blood glucose (mmol/l); (B) body weight ( $\mathrm{g}$ ); (C) water intake (ml/day); and (D) food consumption (g/day) before (Day 0) and after (Day 7) STZ treatment (65 mg/kg, i.p.) or its vehicle (Control). Statistical comparison is indicated between Day 0 and Day $7\left({ }^{* * *} P<0.001\right)$ and between control and STZ-treated rats on Day $7(+++P<0.001)$. $n=5$ to 7 rats. 


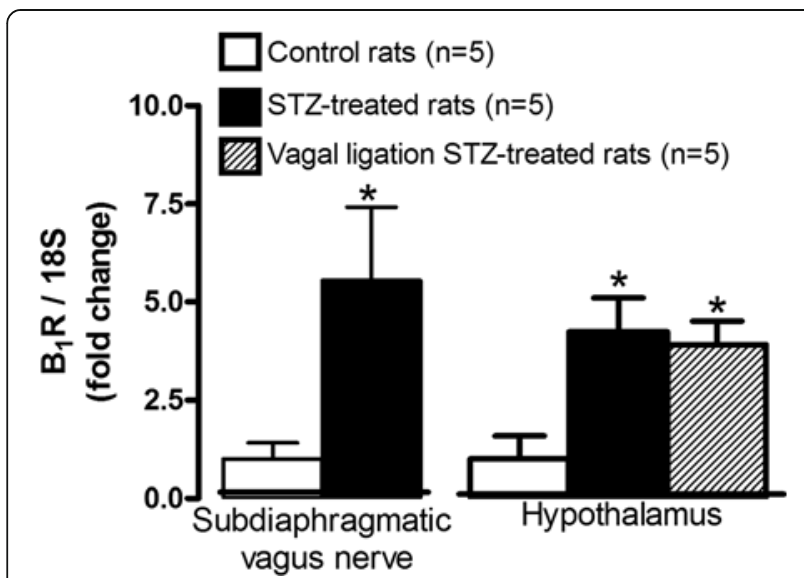

Figure 2 B1R mRNA levels in the subdiaphragmatic vagus nerve and hypothalamus of control and STZ-treated rats. The impact of vagal nerve ligation is also shown on hypothalamic B1R mRNA level. Rat 185 was used as a housekeeping gene for quantification. Comparison with control is indicated by * $P<0.05$. $\mathrm{n}=5$ rats.

specificity of B1R labeling was confirmed by the absence of co-localization (no yellow color) with the pre-immune anti-B1R serum (Figure 4).

\section{Effect of B1R stimulation on body temperature in STZ-treated rats}

Three doses of the B1R agonist SDABK and one dose of the agonist DABK were injected i.p. in one-week STZtreated rats to assess their impact on body temperature (Figure 5). The dose of $0.01 \mathrm{mg} / \mathrm{kg}$ SDABK had no effect on body temperature while the dose of $0.1 \mathrm{mg} / \mathrm{kg}$ SDABK increased significantly body temperature at 5,10 and 15 minutes post-injection. The dose of $1 \mathrm{mg} / \mathrm{kg}$ SDABK caused a greater effect $\left(+1.5^{\circ} \mathrm{C}\right)$ which peaked at 10 to 15 minutes post-injection and persisted at least 30 minutes in STZ-treated rats. The latter response was similar to that produced by $5 \mathrm{mg} / \mathrm{kg}$ DABK, whose response was, however, still significant at 60 minutes. Vehicle had no effect on body temperature in STZtreated rats (Figure 5). Vehicle and $1 \mathrm{mg} / \mathrm{kg}$ SDABK had no significant effect on body temperature in control rats (Figure 6). Baseline temperature (time 0 minute) was not significantly different between control and STZ-treated rats (Figure 6).

The hyperthermic response induced by $1 \mathrm{mg} / \mathrm{kg}$ SDABK in STZ-treated rats was significantly reduced by the selective B1R antagonist SSR240612 $(10 \mathrm{mg} / \mathrm{kg}$, gavage), confirming a role for $\mathrm{B} 1 \mathrm{R}$ in this response. SSR240612 had no direct effect on body temperature in control rats (Figure 6) or in STZ rats (not shown) when compared to vehicle values. The intraperitoneal injection of BK $(1 \mathrm{mg} / \mathrm{kg})$ caused a non-significant diminution $\left(-0.6^{\circ} \mathrm{C}\right.$ at five minutes) of body temperature in STZ- treated rats, excluding a possible role for B2R through a peripheral mechanism (Figure 7).

\section{Mechanism of B1R-induced hyperthermia}

Selective inhibitors of NOS, COX-1 and COX-2 were pre-administered to STZ-treated rats to investigate the downstream mediators implicated in B1R-induced hyperthermia. Figure 8 shows that SDABK-induced hyperthermia was prevented by a $2 \mathrm{~h}$ pre-treatment with either L-NAME (30 mg/kg, i.p.) or niflumic acid (15 mg/kg, i.p.) while indomethacin $(10 \mathrm{mg} / \mathrm{kg}$, i.p.) had no significant effect. Inhibitors had no direct effect on body temperature in STZ-treated rats (data not shown). Moreover, B1R-mediated hyperthermia was prevented in rats that underwent subdiaphragmatic ligation of the vagus nerve one week prior to STZ treatment (Figure 8). STZ rats presented no alteration in baseline body temperature after vagal ligation. Sham-operated rats responded normally to SDABK (1 mg/kg) (data not shown).

\section{Discussion}

In addition to providing the first evidence that $\mathrm{B} 1 \mathrm{R}$ is expressed on peptidergic sensory $\mathrm{C}$-fibers in the vagus nerve of STZ-treated rats, data uncovered a pyretic response mediated by the activation of the B1R through a vagal sensory pathway. The hyperthermic response is mediated by $\mathrm{NO}$ and prostaglandins (derived from COX-2). These findings are clinically relevant as kinins and B1R are associated with systemic inflammation. Thus, in addition to causing pain through activation of primary sensory fibers and microglia $[8,11,13]$, edema and vascular hyperpermeability $[17,26]$, and vasodilation $[9,38]$, the kallikrein-kinin system could also contribute to hyperthermia during inflammatory processes.

\section{General mechanism leading to hyperthermia}

Hyperthermia and fever are initiated following exposure to exogenous (bacteria, toxin) or endogenous pyrogens (pro-inflammatory cytokines (IL-1 $\beta$, IL-6 and tumor necrosis factor- $\alpha($ TNF- $\alpha))[1,20,21]$. The classical and controversial view of fever is that pyrogenic cytokines are mostly generated systemically and they act centrally through COX-2 dependent prostaglandin $\mathrm{E}_{2}\left(\mathrm{PGE}_{2}\right)$ and $\mathrm{EP}_{3}$ receptor in the ventromedial preoptic area (VMPO) of the anterior hypothalamus [21]. However, another theory is that the peripheral pyrogenic message is not transmitted via a humoral route but rather by the vagus nerve to the nucleus tractus solitaries, which in turn signals to the VMPO [20]. In that scenario, the contribution of $\mathrm{PGE}_{2}$ derived from COX-2 is essential for the activation of vagal afferents which express $\mathrm{PGE}_{2}$ receptors $\left(\mathrm{EP}_{3}\right)$ while NO is released in the VMPO [20]. 


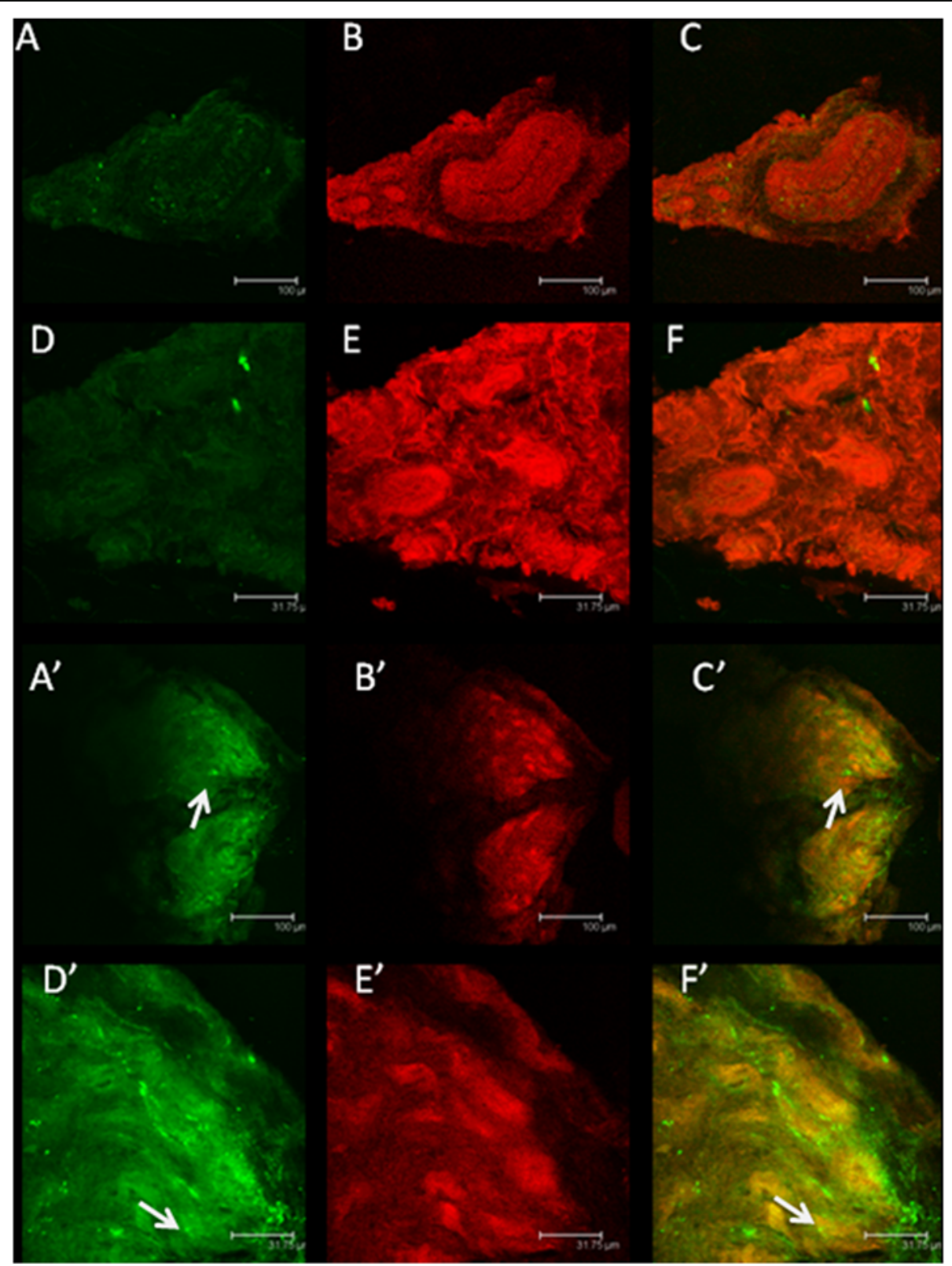

Figure $\mathbf{3}$ Immunolocalization of B1R. Shown are confocal microscopy pictures of coronal sections of subdiaphragmatic vagus nerve isolated from control rats $(\mathbf{A}-\mathbf{F})$ and STZ rats $\left(\mathbf{A}^{\prime}-\mathbf{F}^{\prime}\right)$. B1R $\left(\mathbf{A}-\mathbf{A}^{\prime}, \mathbf{D}-\mathbf{D}^{\prime}\right)$ was labeled with anti-B1R (green spots, arrows). Peptidergic C-fibers (B-B', E-E') were labeled with anti-CGRP (red) and overlay pictures (yellow) showing co-localization were shown in $\mathbf{C}-\mathbf{C}^{\prime}$ and $\mathbf{F}-\mathbf{F}^{\prime}$. Images are representative of at least four sections from four rats per group. Scale bar $=100\left(\mathbf{A}-\mathbf{C}, \mathbf{A}^{\prime}-\mathbf{C}^{\prime}\right)$ or $31.8 \mu \mathrm{m}\left(\mathbf{D}-\mathbf{F}, \mathbf{D}^{\prime}-\mathbf{F}^{\prime}\right)$.

\section{Model of B1R expression}

Our aim was to determine the contribution of a vagal pathway in the regulation of body temperature by B1R. Therefore, we chose an animal model known to express high level of B1R. In STZ-diabetic rats, B1R was induced by hyperglycemia-increased oxidative stress [19,26,39]. $\mathrm{B} 1 \mathrm{R}$ was markedly expressed in various CNS and peripheral tissues [10,30,31], including primary sensory C-fibers [31]. In this model, B1R was associated with diabetic pain neuropathy $[10,40]$, edema [41], leukocyte migration
[42] vascular permeability $[18,26,43,44]$, all cardinal signs of systemic inflammation.

\section{B1R-induced hyperthermia}

Our data suggested that B1R-induced hyperthermia is dependent on both COX-2 and NOS activity as systemic treatment with their specific inhibitors prevented the response of the B1R agonist. Indeed, NO release has been extensively associated with B1R stimulation in STZdiabetic rat $[8,43]$. NO can promote hyperthermia by 


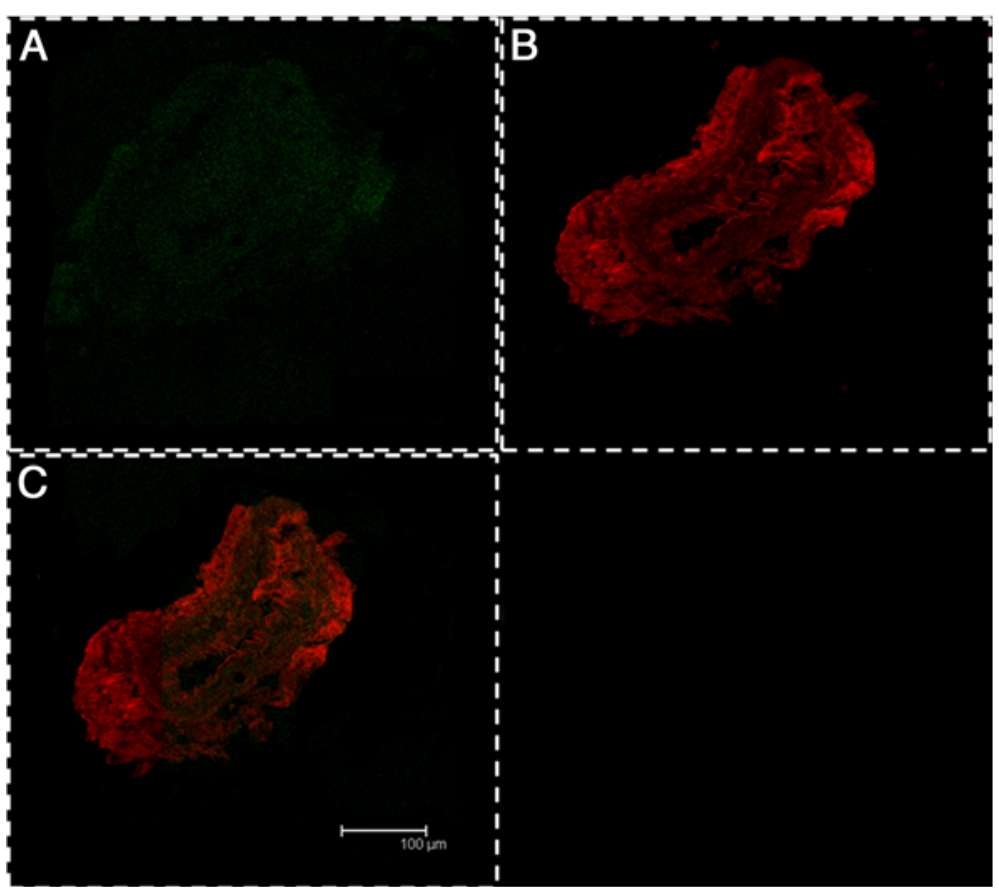

Figure 4 Specificity of B1R antibody for immunolocalization. Shown are confocal microscopy pictures of coronal sections of subdiaphragmatic vagus nerve isolated from STZ rats labeled with pre-immune anti-B1R (A, green) and anti-CGRP (B, red). Picture overlay is presented in panel $\mathbf{C}$ showing no evidence of co-localization (no yellow color). Images are representative of at least four sections from three rats. Scale bar $=100 \mu \mathrm{m}$.

activating surrounding immune cells (macrophages, neutrophils) known for their capacity to release pyrogenic cytokines (IL-1 $\beta$, IL-6 and TNF- $\alpha$ ) [45,46]. Moreover, NO can activate efferent neurons of the central nervous system, which can in turn activate either directly the preoptic area of the hypothalamus $[20,46]$ or indirectly brain microglia and endothelial cells to generate $\mathrm{PGE}_{2}$ [47].

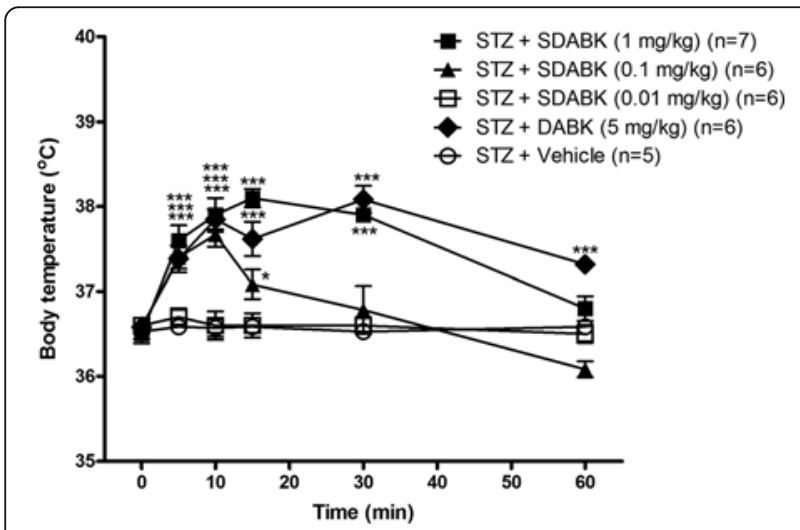

Figure 5 Rectal temperature changes to B1R agonists. Two B1R agonists, SDABK $(0.01,0.1,1 \mathrm{mg} / \mathrm{kg})$ or DABK $(5 \mathrm{mg} / \mathrm{kg})$, were injected intraperitoneally in STZ rats. Statistical comparison with STZ + vehicle ${ }^{*}$ ) is indicated by * $P<0.05$ and ${ }^{* * *} P<0.001 . n=5$ to 7 rats.

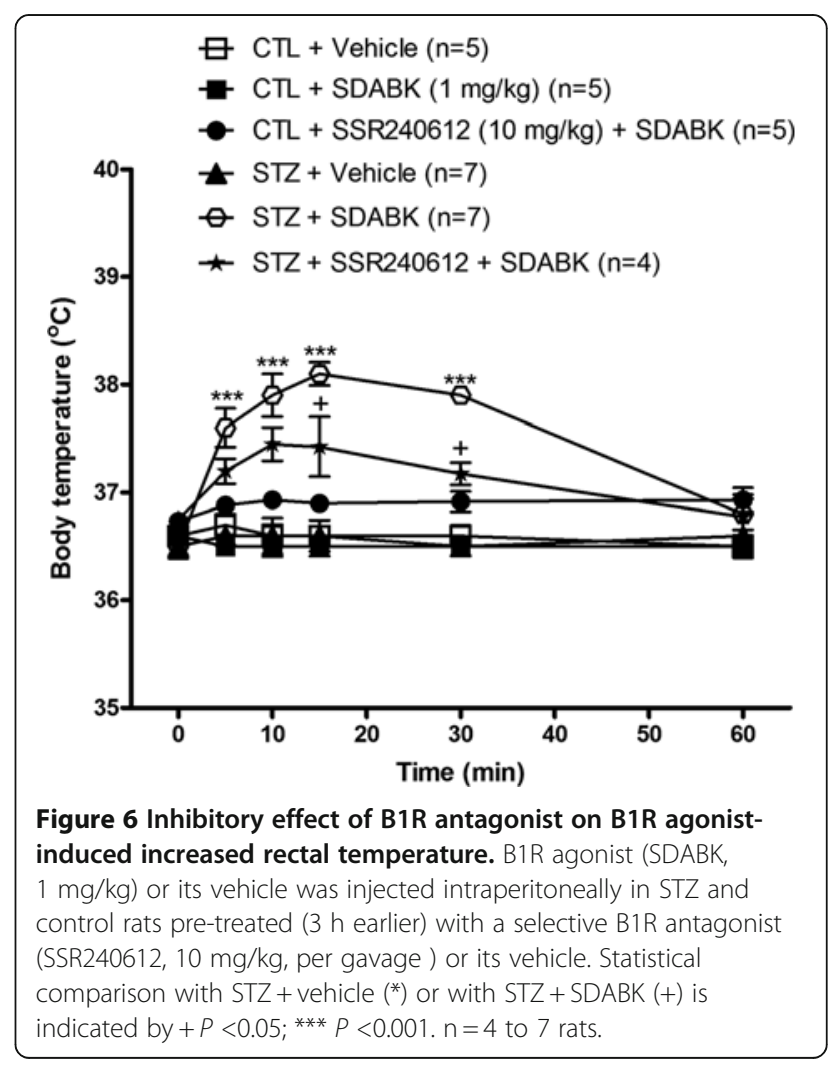




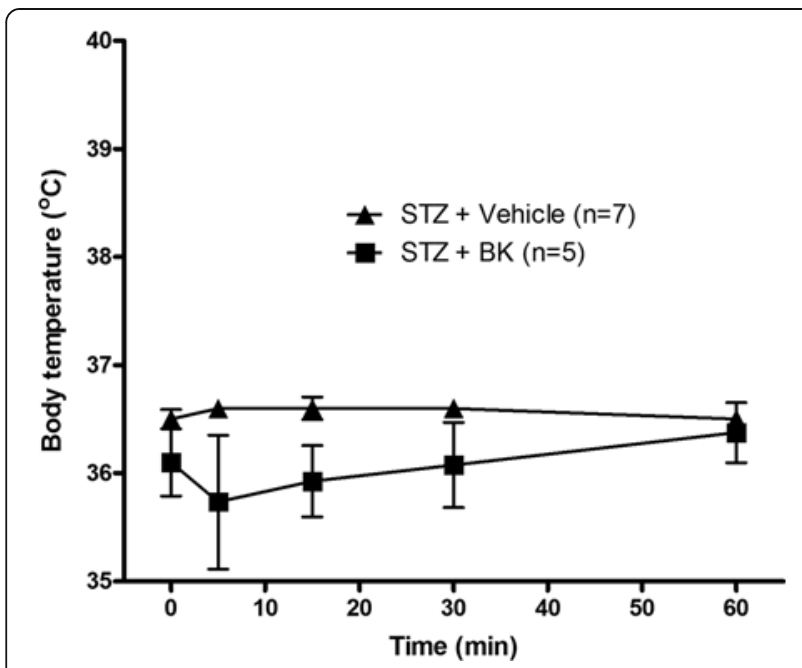

Figure 7 Rectal temperature changes to B2R agonist. Bradykinin (1 $\mathrm{mg} / \mathrm{kg}$ ) was injected intraperitoneally in STZ rats. $n=5$ to 7 rats. Differences between the two curves were not statistically significant.

The enhanced B1R expression (mRNA and protein) on sensory $\mathrm{C}$-fibers of the vagus nerve and the suppression of the B1R agonist-induced hyperthermic response after ligation of the subdiaphragmatic vagus nerve strongly suggest the involvement of a vagal sensory mechanism. The nucleus of the solitary tract is known to receive sensory information from the vagus nerve and to relay it

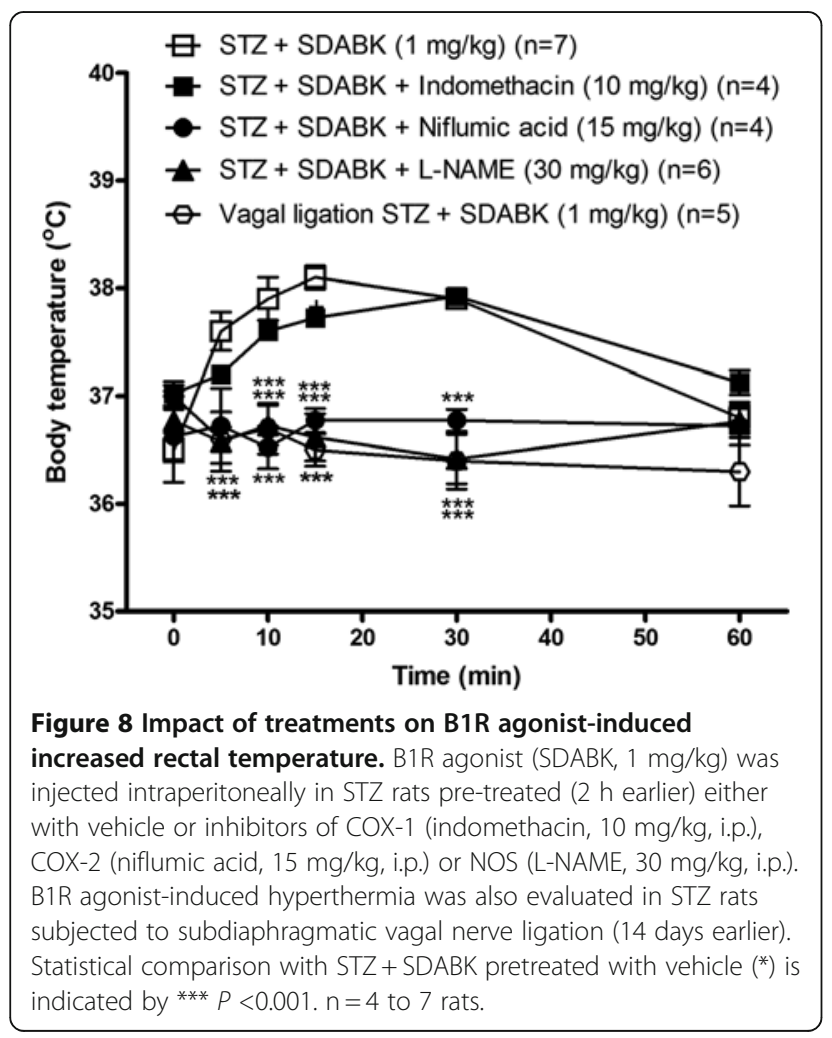

to the thermoregulatory center in the hypothalamus [20]. Additionally, B1R stimulation can release pyrogenic cytokines (IL-1 $\beta$ and TNF- $\alpha$ ), NO and prostaglandins [8], that could in turn activate the vagus nerve. Thus B1R agonist could activate vagal afferents directly and indirectly through inflammatory mediators that may act synergistically to amplify the signal.

An early study reported that i.p. injected LPS induced fever and B1R mRNA expression in the rat hypothalamus. Subdiaphragmatic vagotomy blocked both fever and B1R, but not B2R gene expression, suggesting a primary role for central B1R in the early phase of fever induced by LPS $[48,49]$. In our study, however, the enhanced expression of B1R in the hypothalamus of STZ rats was not affected by vagal nerve ligation, providing further evidence that the pyrogenic response induced by i.p. injected B1R agonist is mediated by a peripheral B1R mechanism.

\section{Conclusion}

This study provides the first evidence that kinin B1R can regulate body core temperature to induce fever through a vagal sensory mechanism involving prostaglandins (via COX-2) and NO. The prevention of fever may represent an additional therapeutic benefit of B1R antagonism during inflammatory processes.

\section{Abbreviations}

BK: Bradykinin; CGRP: Calcitonin-gene-related peptide; COX

1: Cyclooxygenase-1; COX-2: COX-2, Cyclooxygenase-2; DABK: Des-Arg' ${ }^{9}-B K$; DMSO: Dimethylsulfoxide; IL-1B: Interleukin-1 $\beta$; i.c.v.: Intracerebroventricular (ly); i.p.: Intraperitoneal; B1R: Kinin B1 receptor; B2R: Kinin B2 receptor; LPS: Lipopolysaccharide; NOS: Nitric oxide synthase; NO: Nitric oxide; PBS: Phosphate buffered saline; PGs: Prostaglandins; $\mathrm{PGE}_{2}$ : Prostaglandin $\mathrm{E}_{2}$; qRT-PCR: Quantitative real-time PCR; STZ: Streptozotocin; SDABK: Sar-[D-Phe ${ }^{8}$ ] des-Arg ${ }^{9}$-BK; VMPO: Ventromedial preoptic area.

\section{Competing interests}

The authors declare that they have no competing interests.

\section{Authors' contributions}

ST, HG and RC designed the study and analyzed the data. ST, HG and JSD performed the experiments. ST drafted the manuscript. RC wrote the final version of the manuscript. All authors have read and approved the final version of the manuscript.

\section{Acknowledgements}

This work was supported by a Grant-in-aid from the Canadian Institutes of Health Research (CIHR) (MOP-119329). ST holds a Studentship Award from the CIHR (Frederick Banting and Charles Best Canada Graduate Scholarships-Doctoral Award).

Received: 18 May 2012 Accepted: 27 August 2012

Published: 13 September 2012

\section{References}

1. Dinarello CA: Infection, fever, and exogenous and endogenous pyrogens: some concepts have changed. J Endotoxin Res 2004, 10:201-222.

2. Nakamura K: Central circuitries for body temperature regulation and fever. Am J Physiol Regul Integr Comp Physiol 2011, 301:R1207-R1228.

3. Hansen MK, O'Connor KA, Goehler LE, Watkins LR, Maier SF: The contribution of the vagus nerve in interleukin-1beta-induced fever is 
dependent on dose. Am J Physiol Regul Integr Comp Physiol 2001, 280:R929-R934.

4. Werner MF, Fraga D, Melo MC, Souza GE, Zampronio AR: Importance of the vagus nerve for fever and neutrophil migration induced by intraperitoneal LPS injection. Inflamm Res 2003, 52:291-296.

5. Watkins LR, Goehler LE, Relton JK, Tartaglia N, Silbert L, Martin D, Maier SF: Blockade of interleukin-1 induced hyperthermia by subdiaphragmatic vagotomy: evidence for vagal mediation of immune-brain communication. Neurosci Lett 1995, 183:27-31.

6. Laye S, Bluthe RM, Kent S, Combe C, Medina C, Parnet P, Kelley K, Dantzer R: Subdiaphragmatic vagotomy blocks induction of IL-1 beta mRNA in mice brain in response to peripheral LPS. Am J Physiol 1995, 268:R1327-R1331.

7. Dias JP, Talbot S, Senecal J, Carayon P, Couture R: Kinin B1 receptor enhances the oxidative stress in a rat model of insulin resistance: outcome in hypertension, allodynia and metabolic complications. PLoS One 2010, 5:e12622.

8. Couture R, Harrisson M, Vianna RM, Cloutier F: Kinin receptors in pain and inflammation. Eur J Pharmacol 2001, 429:161-176.

9. Couture R, Girolami JP: Putative roles of kinin receptors in the therapeutic effects of angiotensin 1-converting enzyme inhibitors in diabetes mellitus. Eur J Pharmacol 2004, 500:467-485

10. Talbot S, Chahmi E, Dias JP, Couture R: Key role for spinal dorsal horn microglial kinin B1 receptor in early diabetic pain neuropathy. J Neuroinflammation 2010, 7:36.

11. Talbot S, Couture R: Emerging role of microglial kinin B1 receptor in diabetic pain neuropathy. Exp Neurol 2012, 234:373-381

12. Talbot S, Dias JP, Lahjouji K, Bogo MR, Campos MM, Gaudreau P, Couture R: Activation of TRPV1 by capsaicin induces functional kinin $B(1)$ receptor in rat spinal cord microglia. J Neuroinflammation 2012, 9:16.

13. Calixto JB, Medeiros R, Fernandes ES, Ferreira J, Cabrini DA, Campos MM: Kinin B1 receptors: key G-protein-coupled receptors and their role in inflammatory and painful processes. Br J Pharmacol 2004 143:803-818.

14. Regoli D, Barabe J: Pharmacology of bradykinin and related kinins. Pharmacol Rev 1980, 32:1-46.

15. Leeb-Lundberg LM, Marceau F, Muller-Esterl W, Pettibone DJ, Zuraw BL: International union of pharmacology. XLV. Classification of the kinin receptor family: from molecular mechanisms to pathophysiological consequences. Pharmacol Rev 2005, 57:27-77. doi:27.

16. Marceau F, Regoli D: Bradykinin receptor ligands: therapeutic perspectives. Nat Rev Drug Discov 2004, 3:845-852

17. de Blois D, Horlick RA: Endotoxin sensitization to kinin $B(1)$ receptor agonist in a non-human primate model: haemodynamic and pro-inflammatory effects. Br J Pharmacol 2001, 132:327-335.

18. Abdouh $M$, Talbot $S$, Couture R, Hassessian HM: Retinal plasma extravasation in streptozotocin-diabetic rats mediated by kinin $\mathrm{B}(1)$ and $\mathrm{B}(2)$ receptors. Br J Pharmacol 2008, 154:136-143.

19. Ismael MA, Talbot S, Carbonneau CL, Beausejour CM, Couture R: Blockade of sensory abnormalities and kinin $B(1)$ receptor expression by $\mathrm{N}$-acetyl-L-cysteine and ramipril in a rat model of insulin resistance. Eur J Pharmacol 2008, 589:66-72.

20. Blatteis $C M$ : The onset of fever: new insights into its mechanism. Prog Brain Res 2007, 162:3-14

21. Romanovsky AA, Almeida MC, Aronoff DM, Ivanov Al, Konsman JP, Steiner AA, Turek VF: Fever and hypothermia in systemic inflammation: recent discoveries and revisions. Front Biosci 2005, 10:2193-2216

22. Coelho MM, Oliveira CR, Pajolla GP, Calixto JB, Pela IR: Central involvement of kinin $\mathrm{B} 1$ and $\mathrm{B} 2$ receptors in the febrile response induced by endotoxin in rats. Br J Pharmacol 1997, 121:296-302.

23. Silva TC A, Pela IR: Changes in rectal temperature of the rabbit by intracerebroventricular injection of bradykinin and related kinins. Agents Actions 1978, 8:102-107.

24. Rao PJ, Bhattacharya SK: Hyperthermic effect of centrally administered bradykinin in the rat: role of prostaglandins and serotonin. Int $J$ Hyperthermia 1988, 4:183-189.

25. Caldeira JC, Franci CR, Pela IR: Bilateral lesion of hypothalamic paraventricular nucleus abolishes fever induced by endotoxin and bradykinin in rats. Ann N Y Acad Sci 1998, 856:294-297.

26. Pouliot M, Talbot S, Senecal J, Dotigny F, Vaucher E, Couture R: Ocular application of the kinin B1 receptor antagonist LF22-0542 inhibits retinal inflammation and oxidative stress in streptozotocin-diabetic rats. PLOS One 2012, 7:e33864.

27. Regoli D, Dion S, Rhaleb NE, Drapeau G, D'Orleans-Juste P: Vasoactive peptides and their receptors. Blood Vessels 1990, 27:137-145.

28. Regoli D, Jukic D, Gobeil F, Rhaleb NE: Receptors for bradykinin and related kinins: a critical analysis. Can J Physiol Pharmacol 1993, 71:556-567.

29. Zuccollo A, Cueva F, Frontera M, Navarro M, Catanzaro O: The role of the kallikrein-kinin system in type I diabetes (insulitis). Immunopharmacology 1996, 33:349-350.

30. Campos MM, Ongali B: De Souza Buck H, Schanstra JP, Girolami JP, Chabot JG, Couture R: Expression and distribution of kinin B1 receptor in the rat brain and alterations induced by diabetes in the model of streptozotocin. Synapse 2005, 57:29-37.

31. Talbot S, Theberge-Turmel P, Liazoghli D, Senecal J, Gaudreau P, Couture R: Cellular localization of kinin B1 receptor in the spinal cord of streptozotocin-diabetic rats with a fluorescent [Nalpha-Bodipy]-des-Arg9bradykinin. J Neuroinflammation 2009, 6:11.

32. Morissette G, Sabourin T, Adam A, Marceau F: Inhibition of human and rabbit arterial smooth muscle cell migration mediated by the kinin B1 receptor: role of receptor density and released mediators. Can J Physiol Pharmacol 2006, 84:1107-1119.

33. Pilon M, Wu R, Huot-Marchand JE, de Blois D, Champlain J, Couture R: Effect of chronic inhibition of nitric oxide on hypertension, insulin resistance, and cardiovascular remodeling in glucose-fed rats. J Cardiovasc Pharmacol 2009, 53:405-413.

34. Brueggemeier RW, Diaz-Cruz ES, Li PK, Sugimoto Y, Lin YC, Shapiro CL: Translational studies on aromatase, cyclooxygenases, and enzyme inhibitors in breast cancer. J Steroid Biochem Mol Biol 2005, 95:129-136.

35. Gougat J, Ferrari B, Sarran L, Planchenault C, Poncelet M, Maruani J, Alonso R, Cudennec A, Croci T, Guagnini F, Urban-Szabo K, Martinolle JP, Soubrié P, Finance O, Le Fur G: SSR240612 [(2R)-2-[((3R)-3-(1,3benzodioxol-5-yl)-3-[((6-methoxy-2-naphthyl)sulfonyl]amino] propanoyl) amino]-3-(4-[[2R,6S)-2,6-dimethylpiperidinyl]methyl]phenyl)-N-isopropyl - $\mathrm{N}$-methylpropanamide hydrochloride], a new nonpeptide antagonist of the bradykinin B1 receptor: biochemical and pharmacological characterization. J Pharmacol Exp Ther 2004, 309:661-669.

36. Kwon HY, Chang TM, Lee KY, Chey WY: Vagus nerve modulates secretin binding sites in the rat forestomach. Am J Physiol 1999, 276:G1052-G1058

37. Lin JC, Talbot S, Lahjouji K, Roy JP, Senecal J, Couture R, Morin A: Mechanism of cigarette smoke-induced kinin $B(1)$ receptor expression in rat airways. Peptides 2010, 31:1940-1945.

38. Loiola RA, Reis FC, Kawamoto EM, Scavone C, Abdalla DS, Fernandes L, Pesquero JB: Role of vascular Kinin B1 and B2 receptors in endothelial nitric oxide metabolism. Peptides 2011, 32:1700-1705.

39. Lungu C, Dias JP, Franca CE, Ongali B, Regoli D, Moldovan F, Couture R: Involvement of kinin B1 receptor and oxidative stress in sensory abnormalities and arterial hypertension in an experimental rat model of insulin resistance. Neuropeptides 2007, 41:375-387.

40. Gabra BH, Merino VF, Bader M, Pesquero JB, Sirois P: Absence of diabetic hyperalgesia in bradykinin B1 receptor-knockout mice. Regul Pept 2005, 127:245-248.

41. Campos MM, Cabrini DA, Cardozo AH, Rae GA, Toro JH, Calixto JB: Changes in paw oedema triggered via bradykinin $\mathrm{B}(1)$ and $\mathrm{B}(2)$ receptors in streptozotocin-diabetic rats. Eur J Pharmacol 2001, 416:169-177.

42. Vianna RM, Ongali B, Regoli D, Calixto JB, Couture R: Up-regulation of kinin $B 1$ receptor in the lung of streptozotocin-diabetic rat: autoradiographic and functional evidence. $\mathrm{Br} J$ Pharmacol 2003, 138:13-22.

43. Catanzaro O, Labal E, Andornino A, Capponi JA, Di Martino I, Sirois P: Blockade of early and late retinal biochemical alterations associated with diabetes development by the selective bradykinin $\mathrm{B} 1$ receptor antagonist R-954. Peptides 2012, 34:349-352.

44. Lawson SR, Gabra BH, Nantel F, Battistini B, Sirois P: Effects of a selective bradykinin $B 1$ receptor antagonist on increased plasma extravasation in streptozotocin-induced diabetic rats: distinct vasculopathic profile of major key organs. Eur J Pharmacol 2005, 514:69-78.

45. Scapini P, Lapinet-Vera JA, Gasperini S, Calzetti F, Bazzoni F, Cassatella MA: The neutrophil as a cellular source of chemokines. Immunol Rev 2000, 177:195-203. 
46. Conti B, Tabarean I, Andrei C, Bartfai T: Cytokines and fever. Front Biosci 2004, 9:1433-1449.

47. Blatteis CM: The afferent signalling of fever. J Physio/ 2000, 526:470.

48. Souza GEP, Piza AM, Peroza EA, Couture R, Lindsey CJ: Vagotomy blocks LPS-induced fever and bradykinin B1 receptor gene expression in rat hypothalamus. Brain Res 2000, 848:39. Abstract.

49. Roth J, Souza GEP: Fever induction pathways: evidence from responses to systemic or local cytokine formation. Braz J Med Biol Res 2001, 34:301-314.

doi:10.1186/1742-2094-9-214

Cite this article as: Talbot et al: Activation of kinin B1 receptor evokes hyperthermia through a vagal sensory mechanism in the rat. Journal of Neuroinflammation 2012 9:214.

\section{Submit your next manuscript to BioMed Central and take full advantage of:}

- Convenient online submission

- Thorough peer review

- No space constraints or color figure charges

- Immediate publication on acceptance

- Inclusion in PubMed, CAS, Scopus and Google Scholar

- Research which is freely available for redistribution 